\title{
Estados Unidos y el nuevo equilibrio en América Latina
}

\begin{abstract}
James PETRAS es autor de numerosos articulos aparecidos en el British Journal of Sociology, American Sociological Revue, Marcha, Desarrollo Económico, New Lefl Revue y otras publicaciones profesionales y politicas. Ejerce como profesor de Ciencia Politica y Administración Pública en Pennsylvania State University, en la cual es director de los estudios sobre Desarrollo de América Latina (un proyecto de investigación). Es coautor de Latin America Reform or Revolution y Politics and Social Forces in Chilean Development.
\end{abstract}

Un nuevo equilibrio político se ha establecido en Latinoamérica. Este equilibrio es producto de la política del gobierno de los Estados Unidos en el período posterior a la revolución cubana, de la orientación política y actitud de los dirigentes latinoamericanos y del curso de acción adoptado por los partidos comunistas de orientación soviética en América Latina.

Para comprender cómo estos factores han producido en realidad el nuevo equilibrio y los actos que contiene, examinaremos la ideologia y las medidas tomadas por los dirigentes norteamericanos y describiremos el curso de acción de la política de los Estados Unidos, a la cual denominaremos como politica 'posterior a la Alianza'.

En la sección final describiremos las consecuencias de la política norteamericana, el modo en que ha influido sobre las perspectivas de reforma social y económica en Latinoamérica y la viabilidad del nuevo equilibrio.

\section{Política de LOS ESTADOS UNIDOS: IDEOLOGÍA Y PRÁCTICA}

La revolución social no es inminente en toda América Latina, a pesar de la considerable agitación en ciertos países y clel desarrollo continuo de la revolución cubana ${ }^{1}$. La presencia abrumadora de los Estados Unidos en las

\footnotetext{
IEn años recientes, el conflicto social en forma de violentas confrontaciones entre las masas populares $y$ la policia ha sido especialmente intenso en los paises mais desarrollados de Latinoamérica, Uruguay, México, Argentina, y en las regiones más industrializadas dentro de cada pais (Rio de Janeiro, Santiago, Lima, etc.). Para una discusión más detallada sobre las probabilidades de un cambio revolucionario ver mi anterior articulo "Revolution and Guerrilla Miovements in Latin America: Venezuela, Guatemala, Colombia and Peru" en Latin America Reforn or Revolution por James Petras y Maurice Zeitlin (New York: Fawcett 1968) pp. 329-369. Para una evaluación algo diferente vea "The Legacy of Che Guevara" por Norman Gall, Commentary, diciembre 1967, pp. 21-44. Sobre el desarrollo de Cuba ver The Transformation of Political Cullure in Cuba, de Richard Fagan (Stanford, California: Stanford University Press, 1969). The Economic Transformation of Cuba por Edward Boorstein (New York: Monthly Review, 1958). Revolutionary Politics and The Cuban W'orking Class por Maurice Zeitlin (Princeton, New Jersey: Princeton University Press, 1967). The Origin of Cuban Socialism por James O'Connor (Cornell University Press, proximo a salir). Un bien informado, pero mal titulado articulo es Problem for Cuba: Matching Promises with Performance de Juan de Onis, . Iew York Times, marzo II, Ig68, pp. 1 y 16.
} 
James Petras / Estados Unidos y el nuevo equilibrio en América Latina

instituciones económicas, politicas, militares y sociales de Latinoamérica es a la vez causa y consecuencia de la ausencia de revolución social ${ }^{2}$. Los años posteriores a 1962 fueron un periodo de contrarrevolución y no un período de insurgencia revolucionaria latinoaméricana a imitación de la revolución cubana. Estados Unidos estaba a la ofensiva previniendo la revolución, apoyando regimenes militares, organizando fuerzas contrainsurgentes y llevando a cabo una ocupación militar. Sin embargo, la ofensiva contrarrevolucionaria norteamericana tuvo el innegable efecto de destruir los fundamentos del mayor supuesto en que se apoyaba la hegemonía de Estados Unidos en América Latina: la ideología de la 'armonía de intereses .

Un poco antes del comienzo de la Segunda Guerra Mundial y prolongándose a través de la Guerra Fría, los expertos y periodistas de asuntos latinoamericanos empezaron a hacer circular la idea de una 'armonía de intereses' entre los Estados Unidos y América Latina ${ }^{4}$. A los Estados Unidos, como la potencia reconocida del hemisferio, esta ideología le era muy favorable. El poder dominante del statu que desea justificar el mantenimiento del sistema de orden y paz a través del cual lleva a cabo la explotación ${ }^{5}$. La idea de la 'armonia de intereses' provee la justificación requerida para la cooperación y la intervención en defensa del interés general de prevenir los cambios violentos y radicales.

El tema de la 'armonía de intereses' fue presentado por los Estados Unidos primeramente bajo los términos de: 'Política del Buen Vecino', 'Panamericanismo' o 'Sistema Interamericano' $y$, finalmente, como 'Alianza para el Progreso'. Como contraste, el énfasis actual sobre una "Fuerza Interamericana de Paz" confronta la retórica liberal de la 'armonía dę ińtereses' con la realidad de los conflictos que surgen del descontento de

\footnotetext{
2Para un informe sobre el compromiso norteamericano en la politica de Latinoamérica a través de la contra-insurgencia y los programas de acción civica, ver Inlernal Security and Silitary lower por Willard F. Barber y C. Neale Ronning, Ohio State University Press, 1966. En ig68, un ex Ministro del Interior boliviano testifico sobre el importante papel desempeñado por la cla en los asuntos politicos de su pais, .Vew York Times, 25 de agosto, 1968. Para la entrevista completa ver Presencia (La Paz, Bolivia), 18 de agosto. "Arguedas Exposes cis activitics in Latin America". Granma La Habana, 25 de agosto 1968, p. 12. Acerca de la influencia politica Y cconómica ejercida por Estados Unidos en un pais del Caribe, República Dominicana, ver The Violence of Domination: U. S. Power and the Dominican Republic (New York: NAcL, 1967 ), por Fred GorT y Michael Locker. Para una discusión sobre la influencia norteamericana en el Brasil ver Containment and Change por Carl Oglesby y Richard Shaull (New York: Macilillan Company, 1967), pp. 83"97 especialmente, Foreign Investment and the large Enterprise in Latin America: The Brazilian Case por Teotonio dos Santos en la obra citada de Petras y Zeitlin, pp. $431-453$. La revista Ramparts ha documentado la infiltración y el uso en el exterior, inclusa Latinoamérica, te la Asociación Nacional de Estudiantes y de la AfL - clo. Sobre el uso dado por el gobierno norteamericano a organizaciones culturales que han estado activas eu Latinoamérica como frentes de propaganda, ver "The Cultural Cold War: A Sorth History of the Congress for Cultural Freedom" por Christopher Lasch en Towards a New Past: Dissenting Essays in American History de Barton Bernstein (editor) (New York: Random House 1968), pp. 322-359.

aPara una discusiōn más intensa o ideológica ver mi articulo "U. S. - Latin American Studies: A Critical Assessment", Science and Society, Vol. 32, $\mathrm{N}^{\circ} 2$ (Primavera de 1968), pp. $144^{8-168 .}$

'En el mismo lugar.

5 Para una discusión sobre la manipulación de la terminologia de las relaciones internacionales para que se adapten a las necesidades de poder te una nación, ver World Polities de A. F. Organski (New York: Alfred A. Knopl, 1968), pp. 272299. Una interesante disctusión sobre estrategias del statu quo aparece en "Revolutionary Change and the Strategy of the Statu Quo" por Vernon Aspaturian en .Veutralism and Nonalignment de Lawrence W. Martin (editor) (New York: Praeger 1962), pp. 165-195.
} 
las masas, como consecuencia de los efectos negativos de la influencia norteamericana en Latinoamérica.

La intervención y ocupación militar son una expresión clara del conflicto de intereses existente entre sociedades industriales expansionistas, altamente desarrolladas, y naciones dependientes de la exportación.

La intervención militar de 1965 , en la República Dominicana, debilitó la legitimidad intelectual de la noción de una 'armonía de intereses' 6 . Estados Unidos demostró que rechazaba categóricamente la coexistencia con una revolución social (lo que ya había rechazado implicitamente en Guatemala y Cuba). La novedad de la politica norteamericana en la República Dominicana, fue el grado de implicación directa de los Estados Unidos. En la invasión dominicana, los dirigentes norteamericanos hicieron más que planear, montar y financiar una Junta obediente, como lo habían hecho en ocasiones anteriores (por ejemplo, en el fracaso de la Bahía Cochinos); llegaron a comprometer realmente a las tropas norteamericanas, con la esperanza de redimir al impopular sector totalitario del ejército. En la República Dominicana, el ejército, que tradicionalmente era un instrumento de la oligarquía y de los dirigentes estadounidenses, estaba dividido, con uno de sus sectores inclinándose hacia las fuerzas populares, bajo la presión de las masas.

Al derrumbarse el tradicional aparato de control nacional, los dirigentes norteamericanos recurrieron a la 'diplomacia del cañonero'. El ejército de Estados Unidos se convirtió en el substituto de la élite loçal, del mismo modo que antes habia intervenido para crear aquella élité.

La teoria de una 'armonía de intereses' entre Estados Unidos y América Latina no puede explicar el motivo de la presencia de fuerzas militares norteamericanas en la República Dominicana en el pasado ni en el presente, ya que esto está en oposición a los deseos de la gran mayoría de los dominicanos.

El ejemplo de la intervención militar en la República Dominicana no es un caso aislado en el conflicto de intereses. Los dirigentes politicos se oponían a los regímenes democráticos de clase media, a causa de su pretendida 'inestabilidad', y sustentaban a los militares, como a los agentes del desarrollo y la seguridad, proporcionándoles fuerzas militares y consejeros; esto lo hacian en número considerable de países latinoamericanos ${ }^{7}$. Estos

\footnotetext{
${ }^{6}$ Una muy bien documentada relación sobre las bases populares te la revuelta dominicana y la resistencia a la invasión de Estados Unidos la encontramos en "Sociological Aspects of the Dominican Revolution" por Jose Antonio Moreno (disertación doctoral inédita, Department of Sociology, Cornell University, 1967). Una detallada refutación de las justificaciones de la administración de Johnson por la invasión a la República Dominicana es "The Dominican Crises" por Theodore Draper, Commentary, diciembre ig65.

'Hubo una leve oposición, especialmente en el Senado, al nuevo rumbo propuesta por el Ejecutivo. Hablando en defensa de la posiciôn pro-militar y reconviniendo a sus criticos colegas en el Senado, la senadora Margaret Chase Smith, audazmente declaró:

"Algunos respetados miembros del Senado Norteamericano fruncen el ceño frente al hecho de tener compromisos militares con paises latinoamericanos. Nos harian suprimir toda ayuda militar al continente sudamericano. Estay en básico desacuerdo con esto. Lo estoy debido a que, en mi opinión, los mejores amigos que tiene Estados Unidos en Sudamérica
} 
James Petras / Estados Unidos y el nuevo equilibrio en América Latina

indicadores de conflicto se pueden considerar sólo dentro de una armazón teórica que no presuponga que las naciones dominantes y las subordinadas tienen 'intereses comunes'. Por otra parte, la evidencia del conflicto no niega el hecho que ciertăs élites latinoamericanas hayan soportado y se hayan beneficiado con las acciones norteamericanas.

La clara confrontación entre las fuerzas militares de Estados Unidos y el pueblo dominicano sacó a relucir la división existente en todo el hemisferio. Esta división se notó anteriormente en la actitud y acciones subsecuentes de Estados Unidos frente a la revolución cubana. El conflicto entre Cuba y Estados Unidos se produjo por asuntos básicos, tales como: el control de los recursos internos, elección del sistema de desarrollo y el modo de usar los recursos para lograr el desarrollo:

Una evaluación de la politica norteamericana con respecto a América Latina, -la Alianza para el Progreso y su fracaso- revelaría que fue ideada partiendo de la suposición que la revolución cubana exacerbaría los antagonismos latentes y manifiestos entre Estados Unidos y Latinoamérica 9 . Lo que estaba implicito en la mente de los dirigentes norteamericanos, al exponer su estrategia, latinoamericana, después de la revolución cubana, (conflictos crecientes y polarización), fue interpretado por muchos científicos sociales como un augurio de una nueva era de amistad entre Estados Unidos y América Latina ${ }^{10}$.

Las alteraciones y ajustes de la politica norteamericana entre $1960 \mathrm{y}$ 1965 reflejaron cambios en el nivel del conflicto existente entre Estados Unidos, Cuba y el resto de América Latina y en el estado de las relaciones internas entre las fuerzas del continente. La politica norteamericana no coincidió con las demandas que hacian las fuerzas sociales empeñadas en reconstruir su sociedad y en disponer de una nueva base para un desarrollo autóniomo.

En el periodo inicial, cuando Washington consideraba la posibilidad inminente de otras revoluciones al estilo de la cubana, los norteamericanos

son los miembros de las fuerzas armadas, y los principales enemigos del Comunismo son los militares". Congressional Record, 2., de marzo 1962 , pp. 4555-4559.

En el capitulo final de su estudio sobre la politica norteamericana y los militares latinoamericanos, Ronning y Barber señalaron que ". . hay signos de una creciente confianza en soluciones militares a . . amenazas de subversión comunista, mientras, al mismo tiempo, el sistema Kennedy de dar todo nuestro apoyo moral y económico a los llamados gobiernos democráticos ha sido abandonado". Obra citada, p. $24^{2}$.

8 Ver The United Stales and Cuba: Business and Diplomacy 1917-1960 (New Haven: 1960), de Robert F. Smith. Cuba: Tragedy in our Hemisphere de Maurice Zeitlin y Robert Scheer (New York: Grove Press, 1963). "On Cuban

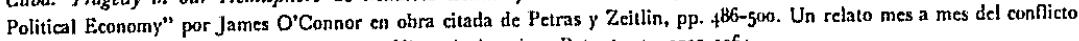
norteamericano-cubano puede encontrarse en Hispanic American Reporl entre 1959-1964.

" "Decline of the Alliance for Progress" de Robert F. Smith en The Great Society Reader de Marvin E. Gettleman y David Mermelstein (editores) (New York: Random House 1967), pp. 372-382. "The United States and Latin America" por J. P. Morray, en obra citada de Petras y Zeitlin, pp. 99-119.

Io Un considerable número de artículos y libros estaban basados en esta suposición. El punto de vista puede encontrarse en U.S. Policy in Latin America por Edwin Lievwen (New York: Pracger 1965), pp. 111-125 especialmente. Y A New Deal for Latin America: The Alliance for Progress, por Lincoin Gordon (Cambridge, Massachusetts: Harvard University Press, igfin). 
toleraron o aceptaron conflictos limitados. Algunos gobiernos, como el de Brasil, proyectaron programas de desarrollo opuestos a las miras de Estados Unidos. En ese momento, cuando el Departamento de Estado considerabaque los intereses norteamericanos se encontraban tempöralmente en gran peligro, Estados Unidos estuvo dispuesto por un corto tiempo a conceder cierta independencia a sus aliados, mientras la situación interna parecia insegura.

Hasta 1962, la politica norteamericana puede ser definida en dos niveles de conflictos: el primero y básico es el de los conflictos estructurales, ejemplo: Estados Unidos-Cuba. Los conflictos secundarios, como los que hubo entre Washington y Brasil durante los gobiernos de Quadros o Goulart, referentes a la nacionalización de alguna firma o comercio privados y a las relaciones con el bloque comunista, estaban sujetos a roces o desgastes tácticos ${ }^{11}$. Estos conflictos secundarios eran tolerados porque los dirigentes norteamericanos le daban prioridad a la contienda principal; o sea, al impacto de la revolución cubana en Latinoamérica.

El mayor defecto del enfoque de la "armonia de intereses" es que no puede incluir todos estos hechos en su estructura teórica. Al contrario, un conflicto modelo de las relaciones entre Estados Unidos y Latinoamérica explicaria los cambios de estrategia y de la politica de los Estados Unidos para con América Latina, en el periodo posterior a la revolución cubana, de la siguiente forma: los dirigentes norteamericanos idearon una estrategia dual, como reacción ante la revolución cubana. Una Alianza para el Progreso, que tenia el fin ostensible de promover las reformas sociales y el desarrollo económico, y el fortalecimiento de las fuerzas militares de Latinoamérica, para asegurar la derrota del Castrismo.

La mayor parte de los fondos de la Alianza se aplicaron en el refinanciamiento de préstamos y el equilibrio de presupuestos y sólo un pequeño porcentaje se usó en proyectos de reformas concretas. Aún más importante, los fondos fueron entregados a una estructura social cuyas élites dominantes no estaban interesadas en reformas agrarias o desarrollos económicos que tocaran sus propiedades (y las de los inversionistas norteamericanos ${ }^{12}$. De ahi que los fondos de ayuda se convirtieran en un

"En 1962, el Secretario de Estado Dean Rusk, refiriẹndose al conficto en Brasil entre la International Telephone and Telegraph Company y el Cobernador Brizola, comentó: "No creo que Estados Unidos pueda permitirse el lujo de arriesgar sus intereses en otros paises en una inversión privada particular en una situación precisa. Tenemos que seguir trabajando en estas cosas". Citado en "The First Ycar: Business", de John Hickey, Inter-American Economic Affairs, Vol. 20, otoño de 1966, p. 63 .

'*El ex Secretario Ayudante para los Asuntos Interamericanos John Moors Cabot declaró: ". . . la necesidad de proteger nuestros principales intereses económicos inevitabiemente da un toque conservador a nuestro plan de acción (en Latinoamérica)" New York Times, 7 de noviembre, 1963 . Sobre la inclinación conservadora de la politica norteamericana ver "Social Revolution in Latin America: The role of U. S. Policy" International Affairs (London), octubre 1965, p. 644, por Robert F. Smith. Aun si consideramos los dos ejemplos, dados por el Departamento de Estado, de paises con espiritu de reforma, Chile y Perú, los informes indican que cl progreso con respecto a la Reforma Agraria ha sido escaso si no nulo. Sobre Chile, ver el Informe del Inter+American Committee on the Alliance for Progress (craP) Washington D. C., noviembre de 1967. Sobre Perú, Una Evaluacion de la Reforma Agraria en Perí. cribs: Panamerican Union, diciembre ig66. En 


\section{James Petras / Estados Unidos y el nuevo equilibrio en América Latina} cemento para fortificar las antiguas élites sociales y protegerlas de los vientos de cambios, en vez de haber sido un estimulo para la aceleración de la reforma.

Simultáneamente, durante el principio de los años 60, aumentó la ayuda militar norteamericana para América Latina en un cincuenta por ciento anualmente por sobre la prestada en la época de Eisenhower ${ }^{13}$.

Al comienzo, Estados Unidos puso su confianza en la clase media para llevar a cabo las reformas socioeconómicas compatibles con el mantenimiento de los intereses económicos norteamericanos y con la politica externa ${ }^{14}$. A medida que cada gobierno escogido por Washington-como muestra de presentación fallaba y aumentaba la intranquilidad popular, el Deparcámento de Estado dependia cada vez más de los gobiernos militares y autoritarios para que éstos hicieran propaganda del éxito y de las obras de la Alianza para el Progreso ${ }^{15}$. Los gobiernos moderadamente liberales, como el de Quadros, Goulart, Bosch, Arosemena, Morales, Frondizi y Paz Estenssoro hicieron evidente su incapacidad para hacer reformas básicas mientras los militares protegieran los intereses de las élites y los de Estados Unidos.

Sin embargo, las esperanzas populares se despertaron ante las promesas de la Alianza para el Progreso y la demagogia de la nativa clase media; y se convirtieron en una fuente de inestabilidad. El populacho en acción entró en disputa con los intereses norteamericanos dentro del pais. Al mismo tiempo, movilizaciones populares en gran escala y siempre en aumento, eran dirigidas por nuevos lideres nacionalistas-populares, los que querian reorganizar la politica externa de Latinoamérica.

A fines de 1962, se tomó la decisión de cambiar las fronteras en la politica norteamericana. En vez de volverse a las fuerzas revolucionarias populares como la alternativa de las fuerzas dirigidas por la clase media, que aunque politicamente democráticas eran impotentes, los dirigentes norteamericanos optaron por lo estable y lo militar. . y, empleando los términos de Rostow, hablaron de ello como una 'nueva fuerza vital modernizadora'16 Se le concedió más importancia a la preservación que a la reforma, a la 'seguridad' que al cambio. Probablemente esto se debió en parte al éxito político obtenido en el bloqueo de Cuba por medios militares.

\footnotetext{
Panamá, ṫa compañia norteamericana Boston Panama Company es dueña de 500.000 acres de tierra, de los que sólo utiliza 5.\%o. Cuando el gobierno panameño intentó recientemente aplicar un impuesto a la tierra no cultivada, la compañia informó a importantes autoridades norteamericanas, se aplicó presián y el gobierno panamero abandonó el asunto. Boston Panama Company, cotrespondencia y documentos inćditos, 17 de junio de Ig6z.

13 El término medio de la ayuda militar norteamericana para Latinoamérica durante los años fiscales de t956-6o (los últimos de Eisenhower) fue de $\$ 31-460.000$. El término medio de ayuda militar para los años fiscales de $1961-65$ fue de 550.260.00). Foreign Assistance and Related Agencies Appropriations Hearing on Appropriations 1967, Housc of Representatives, pp. $77^{2-773}$.

"Barbery Ronning, op. cil. pp. 22-27.

isisma obra, pp. $27-36$.

"IiView From the Seventh Floor de W. W. Rostow (New York: Harper and Row, 1964).
} 
La definición militar de la realidad latinoamericana aumentó en influencia, y la situación en la cual el uso de la fuerza fue aceptada, fue luego transformada sin mayor problema, en una base de apoyo para los golpes militares latinoamericanos y más tarde facilitó el envio de los infantes de marina norteamericanos a la República Dominicana.

Es interesante notar las consecuencias prăcticas de la doctrina de la armonia de intereses para aquellos grupos que apoyaban esta teoria en América Latina. Ellos mismos se dieron el nombre de 'izquierda democrática', colaboraron con Estados Unidos y los militares para aislar a Castro y derrotar a los revolucionarios insurgentes, con el pretexto de las reformas democráticas. Pero, al cambiar el eje político hacia la derecha, los reformistas no sólo derrotaron a la revolución, sino que ellos mismos se convirtieron en blancos de la derecha y, a causa de esto, se debilitaron sus esfuerzos para efectuar reformas. Los dirigentes norteamericanos, al conocer las divisiones e inestabilidad de las relaciones en el hemisferio, pusieron más de dos tercios de los fondos de la Alianza para el Progreso en las manos de dictadores militares o de gobiernos civiles controlados por los militares, a pesar de haber recibido órdenes, anteriormente, de no apoyar a tales regimenes. Se suponía que los fondos de la Alianza para el Progreso eran para fomentar la democracia ${ }^{17}$.

\section{LA CLASE GOBERNANTE EN LATINOAMERICA}

En más de una ocasión los diplomáticos latinoamericanos han criticado duramente la politica de Estados Unidos y luego han ayudado a llevarla a cabo. Las actitudes aparentemente ambiguas de algunos gobiernos latinoamericanos ante los métodos y planes de acción de Estados Unidos en América Latina, pueden ser entendidas considerando tres factores estrechamente relacionados: 1 . La dependencia de las élites y gobiernos latinoamericanos del apoyo económico y militar proporcionado por los Estados Unidos. ${ }^{18} 2$. El temor a las sublevaciones populares internas y 3 . El deseo de imitar las normas de actuación social y politica de Occidente, como ser una cierta independencia politica, un alto grado de consumo, etc.

La intima relación entre estos factores determina el contenido y el estilo de

\footnotetext{
${ }^{27}$ La declaración inicial de propósitos en el documento oficial de la Alianza para el Progreso, "Declaration to the Peoples of America", afirmó categóricamente: "Esta Alianza es establecida sobre el principio básico de que hombres libres trabajando a través de la instisución de la democracia representativa pueden satisfacer mejor las aspiraciones del hombre, inclusive aquellas de trabajo, casa, tierra, salud $y$ escuelas. Ningún sistema puede garantizar real progreso a no ser que atirme la dignidad del individuo, que es el cimiento de nuestra civilización". Alliance for Progress, documento oficial del Consejo Económico y Social Interamericano a Nivel Ministerial realizado en Punta del Este, Uruguay, del 5 al 17 de agosto 196i. (Pan American Union, Washington, D.C. ıg61).

15 Para una relación detallada sobre la dependencia latinoamericana de los Estados Unidos para el entrenamiento, abastecimiento y financiamiento de su milicia, ver la obra citada de Barber y Ronning, capitulos $\mathbf{f}^{-6}$. Estados Unidos es lejos el mayor exportador de bienes manufacturados e importador de materias primas de esta región, además de controlar la mayoria de las materias primas estratégicas de Latinoamérica. Ver un articulo anterior: "U. S. Business and Foreign Policy in Latin America", Neu Politics. Vol. $6, \mathrm{~N}^{\circ}$ 4. pp. $71-\mathrm{Z}_{4}$.
} 
James Petras / Estados Unidos y el nuevo equilibrio en América Latina la aproximación de los dirigentes latinoamericanos a las relaciones
interamericanas.

La ocasional política de ambigüedad de la clase gobernante latinoamericana emerge de su percepción de dos realidades diferentes. Por un lado, su distanciamiento del pueblo y sus necesidades; por otro, el deseo de la élite de conservar su independencia y establecer un standard de vida relativamente confortable. Lo primero impele a la élite hacia Estados Unidos y hacia alianzas para proteger su posición. Lo segundo hace a la élite rebelarse ante la autoridad norteamericana, para poder aprovechar al máximo las oportunidades comerciales y de desarrollo ${ }^{19}$. Las criticas ocasionales, expuestas por diplomáticos latinoamericanos en conferencias hemisféricas, reflejan este tira y afloja, las relaciones internas de fuerzas, las oportunidades externas y las debilidades con que se enfrenta cada grupo a cargo de decisiones.

La intima relación entre estos factores determina el contenido y el estilo de la aproximación de los dirigentes latinoamericanos a las relaciones interamericanas.

La dependencia de las élites latinoamericanas de factores exteriores, refleja su debilidad interior y su incapacidad para movilizar sus recursos domésticos humanos y materiales. A la vez, movilizar recursos internos eficazmente, para el desarrollo nacional, engendraria conflictos de variados niveles con los intereses públicos y privados de Estados Unidos ${ }^{20}$. Además, una movilización verdaderamente efectiva afectaría a los grupos sociales de posición privilegiada establecida. Una politica de movilización de las masas seguramente debilitaria la capacidad de las élites para resistir las presiones sociales populares y tendrian que sacrificar algunos o todos sus privilegios.

La politica del statu quo ha sido y continúa siendo la de la inmovilización de las clases populares. Fundamental en este 'inmolismo' y falta de esfuerzo nacional es la realidad del conflicto social basado en profundas divisiones sociales. La perpetuación de la desigualdad en la distribución de bienes y servicios, en los distintos niveles sociales, es la condición esencial de la existencia de los dirigentes como políticos. Los segmentos más instruídos de la élite procuran incrementar el ingreso nacional, para asi proveer a los cambios marginales, como la forma más eficaz de perpetuar el orden social existente.

Las diferencias dentro de la sociedad no sólo debilitan los esfuerzós serios para efectuar una movilización nacional, sino que también representan una amenaza al orden establecido, forzando a las élites a tener una dependencia

10.El temor de las élites latinoamericanas de perder su actual posición sobrepasa su deseo de asumir un rumba indepen. diente. Sin la ayuda de Estados Unidos, se verian forzadas a afrontar el desasosiego popular interno, contando sólo con los recursos politicos nacionales a disposición de ellas, situación muy poco halagadora.

- Para una discusión más detallada de este punto ver Capitalism and Underdevelopment in Latin America por Andre Gunder Frank (New York: Monthly Review Press 1967). 
dual: 1) Las élites encuentran el substituto para su incapacidad de movilizar los recursos internos en la ayuda económica del extranjero; 2) Las élites buscan el apoyo militar norteamericano, como un contrapëso ante las presiones populares.

Frente a esta dependencia dual, surgen lideres políticos de la élite que adoptan una retórica populista y que aspiran a provocar 'movilizaciones populares limitadas', como una forma de crear esferas independientes para comerciar y negociar con Estados Unidos ${ }^{21}$.

Sin embargo, éste no es el modo de producir un acercamiento duradero y constante. La inestabilidad de estas movilizaciones limitadas y dirigidas desde arriba, es el resultado de la actitud cautelosa adoptada por las élites con tendencias populistas ante los movimientos de masas. Las masas movilizadas tienen que ajustarse a las aspiraciones de poca trascendencia de las élites $y$, sobre todo, debe prevenirse su descontento como seria, por ejemplo, que actuaran en torno a ciertos intereses especificos de clase. La vulnerabilidad de las élites latinoamericanas hace que el desarrollo de un movimiento popular nacional sea un fenómeno de corta vida; por lo menos en lo que concierne a la participación activa de las masas. La burocratización del movimiento de masas, la incorporación en su seno de lideres populares, el aislamiento de los extremistas (aquellos que formulan un programa de cambios más amplios e igualitarios) y el empleo de la coerción física, son algunos de los métodos empleados por una élite que luego de fomentar un movimiento de masas para asuntos específicos y por un tiempo limitado, lo dejan aquietarse finalmente ${ }^{22}$.

Algunas élites latinoamericanas más ilustradas tienen como fin práclico el de una revolución institucional basada en un sistema casi de partido único, tal como en México ${ }^{23}$. La oposición no seria efectiva y los sectores sociales mayoritarios estarian integrados en cuerpos corporativos, los cuales formularian las exigencias marginales al sistema y serian dirigidos por las élites negociadoras.

Lo que hace muy improbable el hecho de que otros paises puedan seguir el

21 Perón en Argentina y Vargas èn Brasil fueron ejemplos de este tipo de jefatura politica popular autoritaria, vease "Populism and Reform in Latin America" de Torcuato Di Tella $y$ "The Dynamics of Brazilian Nationalism" de Helio Jaguaribe en Obstacles to Change in Latin America de Claudio Veliz (editor) (London: Oxford ig66).

*2 Hay varios cjemplos de movimientos politicos que en un tiempo fueron revolucionarios o innovadores $y$ que han sido transformados en máquinas burocráticas relativamente conservadoras. EI Partido Revolucionario Institucional (PRI) en Méjico, en Venezuela el Partido de Acción Democrática (AD), en Bolivia el Movimiento Nacional Revoluciunario (MNK). Todos se iniciaron como movimientos de movilización nacional y terminaron por alienarse y remover a los reformadores de sus cargos. Sobre Mejjicn, ver La Democracia en Méjico de Pablo González Casanova; sobre Bolivia, ver "Revolution in the Hacienda" de William Leons (manuscrito inédito); sobre Venezucla, ver l'enezuela's Fidelistas - Tuı Generations de James Cockcroft (Stanford University Institute of Hispanic American and Luso-Brazilian Studies, 1963).

: $=$ Sobre Méjico, ver La Democracia en Méjico, obra citada, de Pablo González Casanova (Mféjico: Siglo xxı, igfas). Un frustrado intento de acercar la experiencia mejicana a Chile es discutido en mi estudia Chilean Christian Democracy (Berkeley: Institute of International Studies, University of California, 1967). Sobre Argentina, ver El Sistema Politico Argentino y, la Clase Obrera de Torcuato Di Tella (Buenos Aires: Eudera ig6f). 
James Petras / Estados Unidos y el nuevo equilibrio en América Latina

ejemplo de Méjico, es que la revolución mejicana empezó con los campesinos y terminó siendo una revolución institucional dirigida por una clase capitalista dominante y que poseía un mito revolucionario. ${ }^{24} \mathrm{Los}$ poderes que dominaron la etapa revolucionaria no son los mismos que rigen a Méjico hoy dia. La burguesía mejicana es el producto de la revolución y no la constructora de ésta.

Por otra parte, hoy en América Latina todas las fuerzas acumuladas por un prolongado desarrollo capitalista se encuentran presentes en posiciones claves para hacer decisiones ${ }^{25}$.

La presencia en los centros de decisión de modernos directores pertenecientes a corporaciones, sus enlaces con las élites dueñas de las tierras, con los inversionistas extranjeros $y$ con instituciones financieras internacionales influenciadas por Estados Unidos, hacen muy improbable el hecho de que haya una revolución al estilo de la mejicana.

Los estratos medios latinoamericanos residen en posiciones estratégicas de la estructura social, politica y económica y se oponen, neutralizan o contienen a las fuerzas populares insurgentes, las cuales podrian proveer las palancas necesarias para abrir la sociedad, como lo hicieron, parcialmente, en Méjico. A causa de esto, las fuerzas populares latinoamericanas se vuelven, cada vez más, como a un modelo de revolución, hacia la revolución cubana y no hacia la mejicana. Las fuerzas sociales que hicieron posible una revolución 'nacionalista-capitalista' en Méjico dan cada dia más consideración a soluciones revolucionarias colectivistas.

En resumen, el segundo factor que hace surgir y define al nuevo equilibrio - en América Latina, es la ascensión al poder de dirigentes que articulan las acciones e intereses de élites corporativas de tipo comercial, industrial o agricola. Estos grupos comparten con los dirigentes norteamericanos una desconfianza profunda de la politica de movilización de las masas, mientras dependan de la ayuda financiera y militar de Washington.

La politica norteamericana para fomentar la seguridad a través de regimenes autoritarios y la posición de las élites latinoamericanas, han dado forma a un nuevo equilibrio que está a favor de la hegemonia de Estados Unidos y que continúa las normas de dependencia de América Latina.

\section{Partidos Comunistas: LA POLÍtica de la Coexistencia}

Los movimientos de masas, dirigidos desde arriba, han gozado siempre de la participación y apoyo de los partidos comunistas en América Latina.

\footnotetext{
- Pablo González Casanova, en la misma obra, "Mexico: the Lopsided Revolution" por Moisés González Navarro en obra citada de Claudio Véliz, pp. 206-22g.

" Acerca de la ćlite industrial y la clase media ver "The Industrial Elite" de Fernanto H. Cardoso, y "The New Urban Groups: The Middle Classes" por Luis Ratinoff en Elites in Latin America de S. M. Lipset y Aldo Solari (New York: Oxford University Press, 1967 ). También "Aspects of Class Relations in Chile 1850-1960" de Frederick Pike $y$ "The Argentinian Industrialists" por Gustavo Polit en la obra citada de Petras y Zeitlin.
} 
Mientras que los partidos comunistas son frecuentemente militantes activos en los sindicatos obreros y, en un grado mucho menor, en los movimientos campesinos, los dirigentes del partido, en los niveles superiores, continuamente someten al partido a fuerzas progresivas, como ser, regimenes o partidos de la clase media ${ }^{26}$. De modo que los partidos comunistas son grupos militantes de presión y no grupos orientados a tomarse el poder. Sin embargo, a menudo esto basta para que se les ponga fuera de la ley; se unen entonces a la lucha armada. Tampoco explica esto la intención de tomarse el poder (al menos entre los lideres), sino que es un medio para volver a ganar la legalidad y los derechos parlamentarios. La lucha armada misma es un mostrador de regateos destinado a ser negociado entre los lideres comunistas y el gobierno, a menudo a través de intermediarios.

No obstante, generalmente sucede que estas acciones y tácticas entran en conflicto con otras fuerzas revolucionarias, las cuales tienen aspiraciones al poder $^{27}$. Antes de la revolución, Ios comunistas cubanos llamaron a Fidel Castro 'un aventurero pequeño-burgués'28. Hugo Blanco, peruano, lider de los campesinos, fue atacado en la publicación World Marxist Review con el nombre de 'mercenario de la CIA'; este apodo le fue dado por el Partido Comunista Peruano, el que estaba apoyando informalmente al gobierno de Belaúnde ${ }^{29}$.

Desde 1965 en adelante, el Partido Comunista de Venezuela ha estado clamando por una "paz democrática", una vuelta a la legalidad a cambio del cese de la lucha armada ${ }^{30}$. A pesar de que el gobierno todavia no accede formalmente, los comunistas han retirado a todos sus miembros de la

\footnotetext{
${ }^{26}$ A causa de los agudos ataques que Fidel Castro ha lanzado en contra de los partidos comunistas por su revisionismo, éstos están cada vez menos propensos a identificarse abiertamente con sus aliados de la clase media, prefiriendo términos vagos tales como "fuerzas no proletarias". Uno de los jefes comunistas pro-Noscú de más influencia en Latinoamérica puntualizó el plan de acción de ellos en los siguientes términos:

“. . el problema de nuestra temporal alianza con las fuerzas no-proletarias y no-comunistas exige un nuevo enfoque. Nuestros aliados tienen actualmente mucho más oportunidades de marchar hacia adelante, evidentemente no sin vacilaciones y dificultades. Pase lo que pase, está muy lejos de nuestras mentes usarlos en una etapa determinada sólo con el fin de descartarlos en otra. Por el contrario, no podriamos desear nada mejor que cooperar con ellos en forma indefinida. Lo que nosotros los comunistas queremos es un alineamiento progresivo de todos los defensores de la democracia y el socialismo, reconociendo el derecho de cada aliado a participar en todas las etapas del proceso revolucionario y en todos los gobiernos que sean creados por la lucha del pueblo".

"Alliance of the Anti-Imperialist Forces in Latin America" por Luis Corvalán, W'orld Marxist Revieu. Vol. ı, $N^{\circ} 7$, july $19^{67}$, p. $5^{0 .}$

27 Para una relación más detallada ver mi "Revolution and Guerrilla Movements in Latin America", obra citada, pp. 330-350.

25 Sobre las relaciones entre Fidel Castro y el partido comunista cubano ver Cuba: Tragedy in Our Hemisphere, de Zeitlin y Scheer, capitulo 6.

2 ". . el imperialismo norteamericano $y$ la oligarquia peruana han estado buscando un pretexto adecuado para consolidar la posición de la Junta (militar)... (tal pretexto) fue cortésmente proporcionado por los trotskistas. del grupo de Hugo Blanco, quienes mataron a varios policias con el propósito de provocar. Además de tener amplios fondos a su disposición, el grupo de Hugo Blanco cuenta con el apoyo de la prensa norteamericana, quien trata de describirlo, tanto en su pais como en el exterior, como el Defensor del pueblo peruano. Atrocities Commited by Military Junta Warld Marxit Review. Vol. 6, $\mathrm{N}^{\circ} 7$, julio, 1963, p. 85.

30 Largos extractos de las declaraciones de un partido comunista venezolano defendiendo la línea de la paz democrática aparecen en un discurso en el que Fidel Castro ataca la posición de ellos. "Their Attitude toward the Guerrilla struggle will deline the communists in Latin America" Granma, 13 de marzo, 1967.
} 
James Petras / Estados Unidos y el nuevo equilibrio en América Latina

oposición armada y se han puesto de parte del gobierno en una cantidad de ocasiones; hechos que las guerrillas organizadas de las Fuerzas Armadas de Liberación Nacional (FALN) han resistido amargamente.

El Partido Comunísta de Bolivia recháá una estrategia revolucionaria, aun después del golpe militar de Barrientos, y se negó a apoyar a Guevara y las guerrillas ${ }^{31}$. De este modo, los comunistas bolivianos contribuyeron al aislamiento de las guerrillas y facilitaron la labor de las fuerzas militares bolivianas y norteamericanas. El conflicto entre el Partido Comunista Boliviano pro-Moscú y Guevara, simboliza al conflicto entre la politica de coexistencia de Moscú y la politica revolucionaria de América Latina.

Las actuaciones de los partidos comunistas pro-Moscú han contribuido al éxito de la politica de freno de Washington y han facilitado el nuevo equilibrio en América Latina, al debilitar los esfuerzos unificados en la lucha revolucionaria alentando una estrategia reformista.

La Unión Soviética gencralmente considera a Latinoamérica dentro de la esfera de influencia de Estados Unidos. A lo sumo la Unión Soviética desearia ver gobiernos de América Latina lo suficientemente independizados del Departamento de Estado norteamericano, para asi poder establecer lazos diplomáticos y comerciales con ellos y quizás presentar cierta resistencia a la intervención militar de Estados Unidos. Al mismo tiempo, los dirigentes soviéticos esperarian que estos gobiernos 'independientes' no llegaran a identificarse demasiado con la Unión Soviética, ya que asi impondrian obligaciones economicas y politicas muy grandes en la economia y el gobierno de Mloscú ${ }^{32}$. Los soviéticos no tienen ningún interés en comprometerse en otra situación del tipo de la cubana.

El efecto general de las actividades del partido comunista influenciado por la politica soviética, ha sido debilitar seriamente los esfuerzos de revolución social en América Latina. En combinación con el sistema norteamericano de soluciones militares y represivas, el "pragmatismo" y las transacciones comunistas han hecho pagar un precio enorme a la generación revolucionaria posterior a la revolución cubana, en casi todos los paises de Latinoamérica. Mientras Estados Unidos ha fomentado un nuevo equilibrio al aumentar su confianza en regimenes no-liberales, los partidos comunistas han contribuido a la estabilidad de este equilibrio al crear obstáculos para el empleo de métodos más violentos en la lucha politica.

\footnotetext{
at Referencias sobre la oposición del partido comunista boliviano a las guerrillas se eneuentran en "The Diary of Che Guevara" Ramparts 27 de julio, 1966. La . Nouvel Obsercateur 7 de noviembre, 1967. Narcha (Uruguay) 24 de noviembre de 1967. Militant (New York) 24 de noviembre 1967 . World Outlook (New York) 24 de noviembre, 19 gi7.

Fz En 1966, el gobierno ruso, en busta de su interés nacional, otorgó a Chile $S_{50}$ millones en créditos y ayuda, luego que el Gobierno de Frei concluyó un acuerdo por 25 años que garantizaba y aumentaba la inversión privada norteamericana. Más indicador de la baja estima en que la Unión Soviética tiene a la revolución latinoamericana es el hecho de que los rusos otorgaron $\$ 120$ millones en ayuda y créditos a la dictadura brasileña y enviaron misiones culturales $y$ de amistad a Venczuela y Colombia, las qque llegaron a Bogotí el dia en que el comitć central del partido comunista era arrestado. Para una discusión más amplia sobre este punto ver Intervention and Revolution por Richard J. Barnet (New York: New American Library), 1968. También Intervention Against Conmunism por Herbert Dinerstein (Baltimore 1967).
} 
El mayor obstáculo para la creación del nuevo equilibrio no ha sido el comunismo de tendencias soviéticas, sino que el Castrismo. La relación entre la revolución cubana y el desarrollo politico latinoamericano ha sido complicada y cambiante ${ }^{33}$. Entre 1959 y 1962 , los lideres cubanos-apoyaban a una amplia gama de grupos politicos, desde el ala izquierda hasta el nacionalista moderado, incluyendo a personajes como Quadros de Brasil. En el periodo que siguó a la crisis de los cohetes y a la unión más estrecha de Cuba con Moscú, los lideres cubanos empezaron a trasladar su apoyo cada vez más hacia los partidos comunistas oficiales y hacia los nacionalistas del ala izquierda (el MıR de Venezuela y Perú). Durante este periodo, la actitud cubana hacia la politica revolucionaria de Latinoamérica fue contradictoria. Mientras los cubanos pedian una revolución armada, ellos continuaban apoyando a los partidos comunistas (que no tenian ninguna aspiración de este tipo). Yon Sosa, el lider guerrillero guatemalteco, fue denunciado, y la primera Conferencia Tricontinental, en 1266, contó con una preponderancia de comunistas "oficiales" ${ }^{34}$. No obstante, en el enfasis prestado a la lucha armada revolucionaria, en la considerable oposición presentada a las actuaciones de los partidos pro-Moscú y en las declaraciones a favor de la revolución armada, se evidenció en la conferencia un cambio en la politica cubana. A fines de 1966, la dirección revolucionaria cubana trasladó definitivamente su apoyo de los comunistas "oficiales" a los combatientes activos de las guerrillas armadas. Los nacionalistas, comunistas y otros revolucionarios que participaban en las luchas armadas fueron alabados. Una evidencia de esta nueva posición fue la publicación, en Cuba, del llamado a la revolución del Che Guevara ${ }^{35}$. El 13 de marzo de 1967, Castro denunció abiertamente al Partido Comunista oficial de Venezuela y a la Unión Soviética, y defendió a las guerrillas de Venezuela y a todas las demás ${ }^{36}$.

La escalada bélica norteamericana en Vietnam, la intervención militar en la República Dominicana y el subsiguiente desarrollo de una fundamentación razonada para una intervención militar de Estados Unidos en toda América Latina, pueden haber influido en el cambio de Cuba hacia la izquierda. Los movimientos 'fidelistas' han tenido resultados variados en sus esfuerzos para triunfar sobre la hegemonia de la izquierda pro-Moscú en los sectores más radicalizados de la población ${ }^{37}$. Sean cuales sean los

"s Para una detallada relación sobre la cambiante politica exterior cubana, ver The Hispanic dmerican Retport entre $1959-62$.

"s La acusación hecha por Fidel Castro del lider de la Guerrilla de Guatemala Yon Sosa se encuentra en su "Closing Speech to the "Tri-Continental Conference in Havana" Granma (Suptemento especial de la Conferencia Tri-Continental, editado en inglés). La Habana 16 de enero, tg66. Sobre la composicion de la conferencia ver " $\Lambda$ Conference Without Glory and Without a Program" por Adolfo Gilly, MTonthly Review, abril de 1g66, p. 22.

as El articulo de Che Cuevara titulado "Crear dos, tres, muchos Vietnam" fue dado a conocer por cl servicio noticioso cubano Prensa Latina el i 7 de abril de 1967 , $y$ en junio de ese mismo año fue publiendo en la revista de origen cubano $T r i$ continental.

$\Rightarrow 1$ Granma (Havana) i 3 de marzo de lg67.

"77 Ver "Revolution and Guerrilla Movements" de.J. Petras, obra citada, "The Legacy of Che Guevara" de N. Gall. 
James Petras / Estados Únidos y el nuevo equilibrio en América Latina resultados en el futuro, la continuada influencia de los comunistas proMoscú ha ayudado a consolidar el nuevo equilibrio en el presente.

\section{EL NUEVO EQUILIBRIO Y LA POLITICA POSTERIOR A LA ALIANZA}

El nuevo equilibrio ha surgido junto con un enfoque más conservador adoptado por los dirigentes norteamericanos ante los problemas por largo tiempo existentes en Latinoamérica en los campos politico, social y económico.

El conservantismo, que cada dia define más a las actuaciones norteamericanas en Latinoamérica, se puede apreciar de diferentes formas: en el receso de las reformas estructurales y agrarias, a cambio del aumento de los cambios tecnocráticos y de la integración económica; en la promoción de la agricultura y la atenuación de la industralización rápida; en el apoyo y ayuda a dictaduras militares como agencias politicas reconocidas, a expensas de gobiernos elegidos libremente; en la organización de una fuerza militar hemisférica; en la enunciación de la doctrina de intervención unilateral y en la renuncia a los principios de soberania implicados y expuestos en la politica del 'Buen Vecino'.

En abril de i 967 , en la reunión en la cumbre de los jefes de Estado del hemisferio en Punta del Este, Uruguay, fue donde se discutieron algunos cambios importantes. James Nelson Goodsell, corresponsal latinoamericano del Christian Science Monitor y uno de los analistas más sobresalientes de las relaciones entre Estados Unidos y Latinoamérica, hizo un reportaje desde la Conferencia en Punta del Este que decia:

"La integración cconómica ha recmplazado a la reforma social y es ahora el objctivo mayor de la Alianza parn el Progreso

Aun cuando no es parte del plan, Estados Unidos favorece firmemente el asunto de la integración y el Presidente Johnson habló del tema con entusiasmo en la reciente reunión de de Punta del Este...

Un corolario del recmplazo del tema de la reforma social por el de la integración económica, es que la agricultura se adueña del papel de sector clave en el desarrollo económico de la próxima década, papel que pertenecia a la industria. En el concepto original de la Alianza para el Progreso, bosquejado aquí en agosto de r 961 , el desarrollo industrial y su efecto en la vida urbana fueron considerados los elementos claves del razonamiento económico.

Pero esto está cambiando y es muy posible que la agricultura llegue a ser el elemento clave en la década de 1970 .

Sin cmbargo, es un nuevo concepto de agricultura: desatender la reforma agraria $y$, en cambio, dar importancia al aumento de la producción, a la diversificación de la exportación, al perfeccionamiento de créditos e incentivos, a la mejoría del mercado $y$ al fomento de la producción de maquinaria agricola y de fertilizantes. Todas estas características se adaptan perfectamente al molde de la integración económica" xk.

${ }^{3}$ Christian Science Wonitor (27 de abril de 1967), p. 12. 
La nueva orientación hacia la agricultura es un eufemismo para referirse a una alianza con los latifundistas de hoy, que dominan la actividad agrícola debido a su posesión de la tierra y al control que tienen sobre el trabajo de los campesinos. La política de Estados Unidos posterior a la Alianza está explícitamente orientada hacia los grandes latifundistas, contrariamente a los principios y normas de la declaración original de la Alianza para el Progreso ${ }^{39}$.

Esta reversión a una alianza tradicional y el olvido de la retórica 'revolucionaria' de los primeros años de Kennedy y la Alianza para el Progreso, están relacionados con la confianza siempre en aumento en formas dictatoriales de mando político, con una disminución de la confianza en la ayuda económica y con un aumento en el empleo de recursos económicos meramente para facilitar las relaciones comerciales con Estados Unidos ${ }^{40}$. Los dirigentes norteamericanos, confiando en los militares, se sienten seguros de todos los gobiernos del continente del Sur y no sienten ningún apremio por la posible pérdida de la región en favor del comunismo, como lo sentian inmediatamente después de la revolución cubana ${ }^{41}$.

En muchas ocasiones funcionarios norteamericanos han sugerido que la estabilidad $y$ el control de una dictadura pueden ser preferibles a la oposición bajo un gobierno popular. Este enfoque alega que la democracia ocurre por etapas, precedidas por: a) El apoyo franco de una dictadura militar, para eliminar la subversión; b) En la próxima etapa está incluida la

\footnotetext{
3 Uno de los objetivos de la Alianza para el Progreso, tal como quedó formulado en los documentos oliciales, fue: "Para fomentar amplios programas de Reforma Agraria, de acuerdo con las caracteristicas de cada pais, y que lleven, donde sea necesario, al cambio eficaz de estructuras y sistemas de uso y posesión de la tierra injustos; con miras de reemplazar el latifundio y los pequeños propictarios por un sistema de posesión de la tierra equitativo para que con la ayuda de crédito adecuado y oportuno, asistencia técnica y facilidades de mercado y distribución de productos, la tierra pase a ser, para aquel que la trabaja, la base de su estabilidad, el cimiento para su creciente bienestar y la garantia de su libertad y dignidad". Alliance for Progress, documentos oficiales del Consejo Social y Económico Interamericano a nivel Ministerial, celebrado en Punta del Este, Uruguay, 5-17 de agosto 1961 . (Pan American Union, Washington D. C., tg6i).

to Carlos Sanz de Santamaria, Presidente del Comité Interamericano de la Alianza para el Progreso (Cı^P), declaró recientemente que el problema del comercio en Latinoamérica está tomando proportiones criticas. Culpó a las naciones desarrolladas de proporcionar ayuda al mismo tiempo que limitan el acceso a sus mercados. Señaló que esta crisis se debe al hecho de que el aumento de la ayuda es "ayuda restringida": las naciones otorgantes restringen la ayuda a la exportación de sus productos y servicios e imponen limitaciones a las importaciones desde los propios paises subdesarrollados a quienes están tratanda de ayudar. Alliance for Progress W'eekly Newsleller, $\mathbf{j} 6$ de septiembre de 1968 , p. I. EI noventa por ciento de todos los gastos de mercaderias con préstamos de la A.I.D. fueron hechos en corporaciones norteamericanas. U.S. Statistical Alstract, ig67. p. 827 .

"t La expresión de la inseguridad que sinticron los planificadores norteamericanos del sistema, durante los primeros años de la revolución cubana, y en especial después del fracaso para derrocar el gobierno de Castro en el tiempo de la invasión de Bahia Cochinos, se puede encontrar en numerosas declaraciones pủblicas. En marzo de igfa, el presidente Kennedy, hablando a los miembros del Congreso y a los diplomáticos latinoamericanos en la Casa Blanca, declaró:

"Aquellos que poseen riqueza $y$ poder en las naciones pobres deben aceptar su propia responsabilidad. Deben dirigir la lucha por aquellas reformas básicas, las únicas que pueden conservar el edificio de sus sociedades. Aquellos que imposibilitaron la revoluciön pacifica harán que la revolución violenta sea incvitable". President Kennedy Speaks on The Alliance for Progress: Agency for International Development, V.S. Dept. of State/Washington.
}

A mediados de la década del sesenta, el temor a la revolución estaba bastante disminuido. El nuevo sentido de seguridad captado al Sur de la frontera por los responsables de la politica norieameritana fue proclamado por el presidente Johnson, en 1965. " ¿Qué pueden decir ellos?. . parece que nos está yendo bastante bien en la República Dominicana. No hemos tenido una Bahia de Cochinos en Latinoamérica. .." Newsweek, 26 de septiembre, 1966. 
James Petras / Estados Unidos y el nuevo equilibrio en América Latina

eliminación de los opositores populares de los dirigentes norteamericanos; c) La tercera etapa incluye la 'modernización' de los procedimientos de la dictadura, y se establecen estructuras formales que limitan o restringen los movimientos de masas, dando como resultado un gobierno que se ajusta a la política global de Estados Unidos y a los intereses inversionistas norteamericanos. Lincoln Gordon, el Embajador en Brasil durante el periodo en que Estados Unidos apoyaba a las dictaduras militares, explicó este proceso de transición de una dictadura militar a la democracia, después de haber asumido el cargo en la administración de Johnson, de Secretario de Estado Ayudante para los Asuntos Latinoamericanos, diciendo:

\footnotetext{
"La democracia constitucional es la norma deseable para todos los países, pero en mundo entero sólo existen aproximaciones a esta idea Es más realista mirar la democracia como un proceso de tiempo y lugar. Yo estoy más interesado en el propósito y en la dirección que en el status, en cualquier momento" t:.
}

En el nombre del "Futuro Propósito y Dirección", más de un demócrata fue eliminado del proceso politico por las aproximaciones de democracia que interesan a Lincoln Gordon. De acuerdo a este punto de vista, una dictadura militar, como la de Brasil, que Gordon ha alabado con entusiasmo, es la partera de la democracia constitucional. La anterior declaración y otras de estilo similar son una clara desviación del punto de vista tradicional de la democracia constitucional y tienen mucha semejanza con las racionalizaciones favorables a las politicas autoritarias ${ }^{43}$.

En el período posterior a la Alianza, la estrategia de los dirigentes norteamericanos en relación con América Latina ha cambiado hacia la creación de nuevas organizaciones regionales. "Un factor clave en esta nueva estrategia es la promoción hecha por los Estados Unidos para la formación de un Ejército Interamericano.

Los asuntos implicados en un Ejército Interamericano $y$ en la intervención militar, los han discutido el Secretario de Estado y los Ministros de Relaciones Exteriores de los Estados Americanos. En la práctica, la cuestión ya ha sido resuelta en gran parte. Estado Unidos está comprometido con sus propias fuerzas militares en varios países latinoamericanos, a instancia de algunos gobiernos, los mismos que están ostensiblemente presentando objeciones de 'principios' ante el intervencionismo. Por ejemplo, las fuerzas de combate norteamericanas han estado o están activas en Perú, Bolivia, Guatemala, Venezuela, Colombia, República Dominicana y otros países de Latinoamérica. Las autoridades castrenses norteamericanas han

Newsweek, $3^{1}$ de enero, 1966, p. 54 .

" Hay una considerable similitud entre las declaraciones hechas por los politicos soviéticos, justificando su politica de apoyo a las dictaduras $y$ la intervención, $y$ aquellas hechas por los planificardores de la acción politica norteamericana. En el caso de la invasión soviética a Checoslovaquia uno encuentra a Kosygin usando frases que podrian haber sido parcial - totalmente extraidas de declaraciones hechas por Johnson durante la invasión norteamerieana a la Repúbliea Dominicana. 
organizado y planeado estrategias militares, durante algún tiempo, contra posibles movimientos nacionales revolucionarios ${ }^{44}$. Como lo indicaron los acontecimientos dominicanos, Washington estaba preparado y presto para intervenir militarmente. Funcionarios de alto rango del Departamento de Estado y el Presidente han declarado en Conferencias Interamericanas y en muchas otras ocasiones que ellos apoyan la intervención contra regímenes izquierdistas ${ }^{45}$.

Sin embargo, en este momento, los gobiernos latinoamericanos prefieren operar sobre bases pragmáticas, aceptando de facto la intervención y oponiéndose a proclamar su dependencia de la fuerza militar norteamericana por razones politicas internas. No obstante, Estados Unidos por tradición y razones internacionales y locales, prefiere tener una base legal para su intervención y esa es la razón de sus esfuerzos para promover un ejército interamericano respaldado por la OEA.

El proceso para aislar a la revolución cubana a través de la consolidación de alianzas bilaterales político-militares está hoy sobrepasado por el concepto de una fuerza militar hemisférica (con miembros de todo el continente), capaz de intervenir en cualquier país de Latinoamérica para reprimir revoluciones populares.

El compromiso siempre en aumento de Estados Unidos en las luchas internas de América Latina fue recalcado por el ex Secretario de Defensa Mc Namara, en declaración ante el Congreso:

\footnotetext{
${ }^{11} \mathrm{La}$ influencia norteamericana sobre las Fuerzas Armadas latinoamericanas ha aumentado considerablemente en los ültimos 5 años. Esto, a su vez ha llevado al creciente control cjercido por los militares latinoamericanos en la vida politica y a la degradación de la libertad politica y la justicia social, contradiciendo las afirmaciones de algunos académicos norteamericanos, de que los cjércitos latinoamericanos llegarian a ser menos politizados con el creciente contacto con los militares de Estados Unidos. La influencia de las misiones militares norteamericanas sobre sus equivalentes latinoamericanos está señalada por numerosos factores: Comando y Plana Mayor de cada uno de los servicios similares a los norteamericanos; en Venezuela, Colombia y Guatemala todos los servicios cumpien la teoria militar norteamericana: la mayoria de los textos usados en las escuelas son traducciones directas, atemás del hecho de que un gran número de oficiales de todas las ramas ha asistido a Escuelas de Servicio en Estados Unidos y otros han recibido entrenamiento anti-subversivo en la Zona del Canal. La ayuda militar norteamericana ha consistido en entrenamiento $y$ asesoria; $y$ en los tres paises anteriormente mencionados los oficiales norteamericanos se han comprometido de hecho en acción al dirigir las fuerzas de combate nacionales. A este respecto, Jas Fuerzas Armadas venezolanas están sujetas a la más estrecha 'asesoria': la misión militar norteamericana de varios centenares de hombres es la mayor en Latinoamerica y es indispensable hasta para lo tocante al procedimiento funcional de la marina venezolana. La misión de la Fuerza Aérea Norteamericana se halla estacionada con cada unidad táctica, en todos los colegios, excepto la escuela de cadetes, como tambièn en el cuartel general de la Fuerza Aérea. (Ver The U. S. Arny Handbook on Venezuela).

15 En septiembre 20 de 1965 la Cámara de Representantes, por una votación de lista de $3^{12}$ contra $5^{2}$ votos, adoptó una resolución (H. Res. $5^{60}$ ) que en realidad sancionó el uso unilateral de la fuerza por cualquier pais del hemisferio occidental. La resolución no mencioná paises, pero como declara el Congressional Quarterly I'eekly Report (24 de septiembre de 1965 ) "parece hecho a la medida para aprobar situaciones tales como la intervención norteamericana en la República Dominicana en abril de 1965 ". H. Res. $5^{60}$ declaró que "la intervención del Comunismo internacional, directa o indirectamente, por muy disfrazada que sea, en cualquiera de los Estados Americanos, entra en conflicto con la politica establecida por las repúblicas americanas para la protección de la soberania de los pueblos de esos estados y la independencia política de sus gobiernos. . .". El juicio de la Cámara expresaba que: "Dada tal situación, una o más de las altas partes contratantes del Tratado Interamericano de Asistencia Reciproca puede dar los pasos necesarios para prevenir o combatir la intervención, dominación, control y colonización en cualquier forma, por las fucrzas subversivas conocidas como Comunismo Internacional y sus agentes en el hemisferio occidental".
} 
James Petras / Estados Unidos y el nuevo equilibrio en América Latina

"Durante el año pasado han sido combatidos con exito ataques terroristas y serias insurgencias en varios paises de Latinoamérica. En otros, han sido contenidas las amenazas politicas.

Venezuela ha podido, estos últimos meses, mejorar substancialmente su control de los elementos guerrilleros $y$ terroristas. Unidades de las fuerzas armadas $y$ de la policia de este pais con adiestramiento norteamericano han dirigido una campaña del gobierno en las ciudades y en el campo.

En Perú, el gobierno ha progresado bastante en su campaña contra las concentraciones de guerrillas; el ejército y la fuerza aćrea peruana, entrenados y apoyados por Estados Unidos, han desempeñado papeles prominentes en la campaña.

En Colombia, el entrenamiento, apoyo y equipo (que incluye varios helicópteros medianos) morteamericanos han ayudado materialmente a las fuerzas armadas colombianas en el cstablecimiento de un control del gobierno en las zonas rurales insurgentes.

En las zonas mineras y ciudades de Bolivia la violencia ha seguido ocurriendo intermitentemente y estamos ayudando a este país para que mejoren el entrenamiento y cl equion de sus fuerzas militares.

La presión sobre el gobierno de Guatemala derivada de las tácticas terroristas, ha aumentado notoriamente este último año. Estamos apoyando a una pequeña fuerza contrainsurgente guatemalteca, con armas, vehiculos, comunicaciones, equipo y entrenamiento.

En Uruguay, el prolongado estancamiento económico ha contribuido a la intranquilidad popular, que culminó recientemente en una seria ola de huelgas en todo el paîs. Nuestro apoyo militar en Uruguay está orientado hacia el mejoramiento de las armas pequeñas, municiones, comunicaciones y equipo de transporte de sus fuerzas de seguridad" s".

La relación del ex Secretario sobre la politica norteamericana en Latinoamérica es una mezcla de eufemismo y evasiones. La referencia de McNamara a la represión de movimientos populares ("control de elementos terroristas y de las guerrillas") va aparejada de un discreto silencio sobre los sistemas sociales explotadores en Latinoamérica, a los cuales Washington está proporcionando "armas, vehículos, comunicaciones y entrenamiento". Según el informe de MicNamara, la politica norteamericana con respecto a los mineros huelguistas de Bolivia (violencia) y los empleados públicos de Uruguay (intranquilidad popular) no consiste en considerar la legitimidad de las demandas sociales y económicas hechas por los sindicatos, sino en "mejorar el entrenamiento y equipo de sus fuerzas militares". Al admitir McNamara que su politica está dirigida contra la "intranquilidad popular" causada por el "prolongado estancamiento económico", da quizás la indicación más clara de que la política norteamericana no está orientada hacia el logro de reformas sociales populares.

En este periodo de despertar popular y de politica de masas, la defensa de los intereses comerciales de América del Norte y del Sur depende de la habilidad de Washington para fortalecer e influenciar al aparato represivo en América Latina. Lo militar ha servido para debilitar o destruir los movimientos de las masas populares.

1" Department of Defense Afppropriations for 1967 Ilearings before a Subcommittec on Apropriations, Housc of Representatives, 8gth Congress, Section Session, U. S. Government Printing Ollice, 1966, pp. $3^{0-34}$. 
ES T U D I OS I $N$ T ER NACIONALE S

Después de que el régimen militarmente sostenido ha establecido planes de acción e instituciones aceptables para los Estados Unidos, se realizan elecciones entre candidatos que sean admisibles a los ojos de los dirigentes norteamericanos. Una táctica similar para la formación de satélites en Europa Oriental fue apodada, hace un tiempo atrás, la 'táctica salame'. Los resultados de las elecciones competitivas que ocurren frente a este fondo de violencia contra las fuerzas populares emergentes, están predeterminados. Las elecciones asi arregladas son entonces utilizadas por Estados Unidos y las élites latinoamericanas como armas de propaganda para legitimar su hegemonia. Una posible consecuencia de esta forma de establecer gobiernos seudolegítimos eś la acumulación de resentimientos en espera de condiciones propicias para otra explosión. El ciclo politico latinoamericano de. violencia-inestabilidad-represión, se prolonga por efecto de la política norteamericana, la cual, a su vez, se convierte en un factor importante del atraso en los cambios estructurales.

En el propuesto Ejército Interamericano se encuentra el esfuerzo más serio para institucionalizar la hegemonia de Estados Unidos en el hemisferio y para proteger los sistemas sociales latinoamericanos. El ex Secretario de Defensa McNamara dio a conocer la explicación que respalda esta estrategia en la siguiente forma:

"Creemos que podria ser útil algún tipo de fuerza reguladora de la paz; que el sistema debicra contar con un procedimiento (arreglo, fórmula) más efectivo y sensible para enfrentar colectivamente un peligro claro $y$ actual para la paz y seguridad del hemisferio. Tal dispositivo, precedente o mecanismo, sustentado por una fuerza resguardadora de la paz, representaria una verdadera distribución de la responsabilidad $y$ detendria momentáneamente a aquéllos elementos que buscan quebrantar la paz.

Crcemos que el problema es cada vez mejor comprendido y continuaremos buscando una fórmula aceptable para nuestros compañeros de la Alianza" '".

El llamamiento de McNamara es para las existentes clases gobernantes de Latinoamérica. Sus temores están dirigidos explícitamente a los revolucionarios nacional-populares y no al 'comunismo internacional' (... situaciones internas... perturben la paz del hemisferio) ${ }^{48}$.

La proposición del ex Secretario de Defensa MIcNamara está destinada a crear una organización multinacional permanente, para legitimar las intervenciones militares norteamericanas como la de la República Dominicana.

Desde el punto de vista del gobierno norteamericano, es evidente la necesidad y el valor de una fuerza interamericana: generaliza la respon-

4. En cl misma lugar.

1- En junio de 1963, el Secretario de Defensa Robert MeNamara declaró: "Hasta alrededor de tgin los programas de ayuda militar para Latinoamérica estaban orientados hacia la defensa del hemisferio. A medida que se esclareció que no habia amenaza de una seria y evidente agresión exterior bacia Latinoamérica, el énfasis se trasladó a las capacidades de seguridad interna". De aqui el rápido crecimiento y expansión de las escuelas antisubversivas de las misiones militares $y$ el intensificado papel norteamericann en la politica latinbamericana. 
James Petras / Estados Unidos y el nuevo equilibrio en América Latina

sabilidad $y$ hace legal el uso de la fuerza para defender el dominio general de Estados Unidos en el hemisferio ${ }^{49}$. Luego, permite que Estados Unidos continúe cosechando los beneficios del control, con un mínimo de costos externos (soldados norteamericanos muertos), lo que podría tener efectos perturbadores dentro de Estados Unidos.

La instalación de bases hemisféricas para entrenamiento militar, la intensificación del compromiso de la A.I.D. y de autoridades militares y cuasipoliticas para arreglar los asuntos político-militares latinoamericanos, el aumento de las asignaciones militares, los lazos estrechos desarrollados entre el personal militar latinoamericano y el norteamericano gracias al programa de acción civica; todo esto ha facilitado el proceso de cooperación militar interamericana ${ }^{50}$.

El primer éxito mayor obtenido para asegurar el apoyo a la fórmula norteamericana de intervención militar en Latinoamérica ocurrió durante el bloqueo de Cuba por Estados Unidos en 1962. Esta acción unilateral de Estados Unidos, que impuso por fuerza sus decisiones en Cuba con la aquiescencia de la Unión Soviética, creó enormes presiones sobre los gobiernos latinoamericanos para que adhirieran.

Cuando Estados Unidos ligó a la cuestión de su predominio en el hemisferio (con derecho a intervenciones unilaterales) la amenaza de una guerra total, los países latinoamericanos no presentaron resistencia. La 'amenaza cubana', que fue la justificación mayor presentada por los dirigentes norteamericanos, fue interpretada por los gobiernos latinoamericanos en dos planos: 1) La amenaza de fuerzas revolucionarias nacionales en sus propios paises; 2) La amenaza del ejemplo de una sociedad socialista desarrollándose con éxito.

La convergencia de estos factores durante el bloqueo cubano - acción militar unilateral de Estados Unidos con efectos globales, la aquiescencia soviética y la deterioración acelerada de las condiciones sociales, económicas y políticas dentro de los países latinoamericanos - facilitaron la aceptación de la intervención en el hemisferio. Del apoyo latinoamericano a la acción

\footnotetext{
"t"El presidente Kennedy trató en parte de dar una coloración positiva al papel históricamente retrógrado que han tenido los militares en Latinoamérica. Acción Civiea pasó a ser el lema y en su mensaje al Congreso del 22 de marzo de 1962, Kennedy declaró: "En cl futuro, ta ayuda militar pondrá mayor énfasis en la seguridad interna, cn las obras civiles y el crecimiento económico de las naciones ayudadas". El principal erecimicnto que inmediatamente experimentaron las naciones latinoamericanas fue la afluencia de más consejeros militares notieamericnnos y sus nombres en forma de siglas: The Military Assistance divisory Croups (MAnG), The Mlobile Training Teams (MrT's), etc.

Por lo menos arece paises en América Latina tienen actualmente programas de acción civico-militar sustentados por Estados Unídos. Bolivia, el primero en organizar Acción Civica en una escala considerable, fue también el primer pais en el cual Estados Unidos reorganizó el Ejército. En la revolución de 1952 fue literalmente destruito el cjército tradicional, para ser reemplazado por milicias populares. Fue gracias a fondos de la a.1.D. que el nuevo cjército boliviano, organizado por los norteamericanos, pudo construir unas pocas escuelas, para luego tomarse el poder e iniciar un ataque frontal contra los mineros del estaño. Un folleto destinado a los comandantes del cjército, bajo el titulo de dección Civica, describe la nueva acción civica politico-militar como un arma contra la subversión de inspiración comunista. Es considerada tanto una medida preventiva como una téenica de guerra de guerrillas antisubversiva.

* Barber y Ronning en la obra citada, capitulos 5-6.
} 
unilateral de Estados Unidos en el bloqueo de Cuba, al consentimiento latinoamericano ante la ocupación norteamericana de la República Dominicana había sólo un paso.

Las fibras morales que sostuvieron el 'nacionalismo' de la clase media por medio siglo se han debilitado consideräblemente. Para muchos gobiernos latinoamericanos es preferible amoldarse a la soberanía norteamericana en el hemisferio, que arriesgarse a una movilización popular que podría debilitar las precarias estructuras sociales. Los diplomáticos latinoamericanos continúan expresando oposición formal ante la intervención de Estados Unidos, pero en la práctica no rechazan la presencia del personal militar norteamericano en América Latina. Esta doble actitud en el asunto de soberanía quizás finalmente pueda resolverse. En el intertanto, las élites latinoamericanas y norteamericanas, enfrentadas a los movimientos populares revolucionarios, no se preocupan demasiado por el idioma hablado por los guardias militares.

En 1968, los militares se encontraban ya muy cerca de un control total de la vịda politica en América Latina ${ }^{51}$. Situaciones que parecían tener un poder dual, en las cuales los gobiernos civiles trataban de maniobrar entre los centros de poder popular y los de poder militar, fueron reducidas gradualmente, pero en forma decisiva, a papeles marginales o eliminadas. Esto fue lo que ocurrió, entre otros casos, con Frondizi en Argentina, Estenssoro en Bolivia, Bosch en la República Dominicana, Goulart en Brasil y Méndez en Guatemala.

El golpe militar de 1964 en Brasil fue un suceso clave en la progresión de la vida politica latinoamericana hacia la militarización ${ }^{52}$. Brasil, el país más grande de América Latina, podía convertirse en el centro de los movimientos revolucionarios autónomos o en un importante aliado-subordinado en la promoción de la política norteamericana. El derrocamiento de Goulart y el implantamiento de la dictadura militar fueron preparados y organizados

51 Los paises latinoamericanos gobernados por juntas militares o por gobiernos establecidos con la intervención directa de los militares incluyen a: Argentina, Bolivia, Brasil, Kepública Dominicana, Ecuador, El Salvador, Guatemala, Haiti, Honturas, Nicaragua, Paraguay y Perú. Una lista cronológica de los golpes militares en Latinoamérica entre los años $195^{6}$ y 1966 se puede encontrar en Hearings Before a Subcommillee on Appropriations House of Representatives: Foreign Assistance and Related Agencies Appropriations for 1967, pp. 62g-630. Una vez que Estados Unidos hubo aprobado a los militares como una fuerza modernizadora-estabilizadora, comenzó un multiplicador de golpes militares. Aparentemente, el golpe militar peruano fue fuertemente influenciado por el de Argentina, el cual, a su vez, fue influenciado por el golpe brasileño aprobado por los Estados Unidos. Malcolm Brown, del Times, observó: "Fuerzas peruanas calificadas sienten que esta vez los jefes inilitares han copiado su acción del golpe argentino de igób. . . Los nuevos gobernantes del Perú editaron un maniliesto sorprendentemente similar en su contenido a un documento del mismo tipo publicado en Buenos Aires durante el golpe argentino". New York Times, 5 de octubre, $1968, p$. I. En verdad, el golpe militar peruano ocurrió poco después de la Séptien Conferencia de Jefes Míilitares en Rio de Janeiro. La Conferencia recalcó el importante papel del cjército en el desarrollo económico, politico y social y en la lucha contra el Castro-Comunismo en Latinoamérica. Ver " $\mathrm{Pc}_{\mathrm{c}}$ rú: El Golpe de Oro Negro", por Maria Elena Ballantine, en Marcha, , de octubre de ı668, p. 20.

T.a En los dieciocho meses siguientes a la toma del poder por los militares en Brasil, en tg6 f, por lo menos siete de los veintitrés gobernadores elegidos fueron removidos de su cargo. Aquellos removidos eran sustituidos por militares leales a la dictadura. En algunos casos, gobernadores tan conservadores en sus puntos de vista sociales y económicos como los militares eran removidos para recalcar el poder $y$ el papel de los militares en el gobierno. Ver Corzeio da Manha, $1^{\circ}$ de abril de $196 j$. 


\section{James Petras / Estados Unidos y el nuevo equilibrio en América Latina}

por el alto comando militar brasileño, apoyado por autoridades y personal militar norteamericano. El éxito de esta aventura 'interamericana' tuvo efectos estimulantes: asegurados del apoyo norteamericano, golpes militares tuvieron lugar en Argentina y Bolivia ${ }^{\text {su }}$. La magnitud del significado para todo el continente de los acontecimientos ocurridos en Brasil no se captó en ese momento. La presencia en el país más grande de América Latina de un personal militar encargado de la política de intervención militar multilateral contra los regímenes políticos izquierdistas, iba a dar sus frutos en el curso de un año. La presencia en la República Dominicana del ejército brasileño junto a las tropas norteamericanas, fue la primera demostración concreta de este sistema. La contrarrespuesta latinoamericana, trágicamente débil, ante la invasión norteamericana de la República Dominicana, señaló el establecimiento real del nuevo equilibrio en América Latina.

El Presidente Johnson indicó la importancia de Brasil y destacó el significado de largo alcance del Ejército Interamericano para la estrategia de Estados Unidos, en su discurso en la Universidad de Baylor el 29 de mayo de 1965. En el debate sobre el éxito militar norteamericano en la supresión de la revolución popular, el Presidente.Johnson dijo:

"Hoy estas realizaciones están garantizadas... garantizadas por las tropas de cinco naciones en representación de este hemisferio. Están bajo el mando del hábil militar brasileño General (Hugo Panasco) Alvin $y$, por primera vez en la historia, la Organización de Estados Americanos ha creado $y$ ha enviado al suelo de una nación americana, una fuerza militar internacional defensora de la paz":s.

Luego el Presidente Johnson lanzó un manifiesto político, una declaración de guerra abierta a todas las revoluciones nacionales populares, a las que puso en el mismo nivel que las 'guerras internacionales'.

"Del crisol dominicano las veinte naciones americanas deben forjar ahora un escudo más fuertc contra el desastre. Hoy está aqui la oportunidad de dar un nuevo paso adelante y" mostrar al mundo el camino para una verdadera cooperación internncional en la causa de la paz y en la lucha para ganar una vida mejor para todos nosotros.

Creemos que el nuevo mundo puede abordar muy cuerdamente esta tarea guiado por nucvas rcalidades.

La primera realidad es que los antiguos conceptos y rótulos son muy anticuados.

En el mundo actual, donde los enemigos de la libertad predican guerras de liberación nacional, la antigua distinción entre guerra civil e internacional ha perdido ya gran parte de su significado.

a El ex Secrelario de Estado Adjunto para Asuntos Interamericanos Thomas Mann estableció claramente la posición de los Estados Unidns: "Yo no soy uno de aquellos que cstán en contra de los militares en Latinoamérica. Creo que los militares son un bastion para la estabilidad" Hearings Before the House Foreign Affairs Commiltee of the House of Representativer to66, p. 157. Sobre la ayuda norteamericana al gobierno militar de Bolivia ver Fareign Assistance and Related Agencies Approprialions Hearings on Approprialions House of Representatives 1956, pp. 1262-1264. Sobre Argentina ver Foreign Assistance and Relaled Appropriations: Hearings on Appropriations 1968 , pp. $739-74^{\text {n. }}$

si U. S. Senate, Congressinnal Recorrl, Procecdings and Debates of the 8gth Congress. First Session, $1^{\circ}$ de junio de 1965, pp. $11697^{-116083 .}$ 
ESTU D I OS I N T ER N A C I O NALES

La segunda realidad es que cuando las fuerzas de la libertad progresan lentamente, ya sea en frentes políticos o económicos o militares, las fuerzas de la esclavitud y la subversión se mueven con rapidez y decisión.

Tercera: sabemos que cuando un grupo comunista quicre aprovecharse de la miseria, todo el libre sistema americano se encuentra en peligro mortal. También sabemos que hoy podemos encontrar estos peligros en muchos de nuestros países.

No existe perturbación en parte alyuna de la que estas fuerzas del mal no vayan a tratar de sacar partido, y podemos esperar más tentativas de obtener el triunfo por el terror $y$ de conquistar por medio del caos.

Cuarta: en la República Dominicana hemos visto que podemos actuar decisivamente y en conjunto.

Quinta: es evidente que necesitamos un nuevo mecanismo internacional preparado para enfrentar los acontecimientos que se mueven velozmente. Cuando sólo horas pueden decidir el destino de generaciones, cl momento de la decisión debe transformarse en el momento de la acción"ss.

La creación real de un Ejército Interamericano aceleraria el proceso de institucionalizar la hegemonia norteamericana en el hemisferio. La formación de un Ejército Interamericano causaria a los países latinoamericanos la pérdida de la condición de cuasisoberania que hasta ahora han mantenido. Las reuniones del alto personal militar son auspiciadas por los dirigentes politicos norteamericanos, para acabar con las actitudes parroquiales e implantar una perspectiva hemisférica. El tema predominante en estas conferencias es la idea de que los estados mayores generales latinoamericanos tienen que desempeñar un papel politico común en una escala continental y que enfrentan a un enemigo común (comunismo y revolución popular) ${ }^{56}$.

El hecho de que las revoluciones populares amenacen al status privilegiado del personal de máxima categoría en Latinoamérica, torna a éste muy bien dispuesto hacia la anterior idea. El fomento de la solidaridad internacional entre los jefes militares es una importante condición previa en la creación de una estructura orgánica para una fuerza militar continental que trascienda los limites nacionales.

La dependencia de los militares del apoyo y dirección de Estados Unidos, los hace especialmente susceptibles a la idea de un Ejèrcito Interamericano. En este sentido, la situación interna encaja a la perfección con las ambiciones hemisféricas de Estados Unidos. A cambio del apoyo para mantener el poder, la élite militar está dispuesta a prestar legalidad a la hegemonía norteamericana en el hemisferio. Sin embargo, el logro de esta aspiración no será inmediato. Algunos gobiernos civiles con bases sociales y politicas un tanto distintas, con diferentes ordenaciones institucionales $y$

ss En cl mismo lugar.

: En mayo de tg65, Estados Unidos por primera vez presentó oficjalmente una resolución pidiendo la formación de una Fuerza Interamericana en la Décima Reunión de Consulta de los Ministros Americanos de Relaciones Exteriores. De más está decir que Estados Unidos puto reunir los votos necesarios para que la medida fuese aprobada. Ver obra citada de Ronning y Barber. Appendix 1, pp. 299-305. 
James Petras / Estados Unidos y el nuevo equilibrio en América Latina públicas, no están en condiciones o bien no desean tener inmediatamente un cambio tan drástico en su posición internacional ${ }^{57}$.

\section{El Nuevo equilibrio Y LA NUEVA IZQUIERda REVOLUCIONARIA}

Coexistencia pacífica es el nuevo nombre para el antiguo tipo de política llamado 'esfera de influencia'. La coexistencia pacifica es un intento hecho por los dos bloques de poder para estabilizar la politica mundial mediante acuerdos que satisfagan a los intereses nacionales. Pero lo que conviene a los intereses nacionales soviéticos, es lo mismo que conviene a Latinoamérica (por lo menos asi lo ven los líderes del momento). La persistencia de la hegemonía norteamericana en América Latina ha causado creciente inestabilidad. La politica de coexistencia pacífica seguida por la Unión Soviética y los partidos que fraternizan con ella en América Latina choca con las necesidades sociales y los problemas económicos con que se enfrentan las sociedades dependientes de Latinoamérica. Las estrategias dictadas por la politica comunista de coexistencia pacífica, en un continente subdesarrollado cuyas desigualdades sociales son mantenidas o acentuadas por la presencia de empresas económicas norteamericanas y por los regímenes militares apoyados desde el exterior, presentan obstáculos adicionales a cualquier cambio social o politico que se oponga a los intereses de Estados Unidos ${ }^{53}$.

La próspera alianza entre los dirigentes políticos norteamericanos y los gobiernos militares ha obligado a las fuerzas reformistas de la izquierda, que están comprometidas con sus objetivos, a buscar medios revolucionarios para lograr sus fines de reforma. El éxito norteamericano en Latinoamerica ha ensanchado la brecha entre los fines reformistas y la capacidad de los grupos políticos para utilizar los procedimientos parlamentarios electorales para llevarlos a cabo.

A los prolongados efectos de inestabilidad de la politica de Estados Unidos en el desarrollo económico y social de América Latina, debemos agregar los efectos radicalizadores en su desarrollo politico. El éxito militar de Estados Unidos se logra al precio de un creciente aislamiento politico y de la polarización entre el personal no perteneciente al gobierno.

\footnotetext{
"Hasta ahora, Méjico y Chile se han opuesto a la idea de una Fuerza Armada Interamericana. Méjico tiene una historia Ilena de intervenciones norteamericanas $y$ un numeroso sector de la opinión pública que se opone a cste tipo de intervención. Chile posee una numerosa clase trabajadora de orientación marxista y una substancial clase media nacionalista que se opondria fuertemente a tal politica. Estos grupos están representados en los comunistas, socialistas y el alzamiento del partido demócratacristiano. quienes en corijunto controlan la mayoria del electorado.

sf Ver A. Gunder Frank en la obra citada, y para una exposición más general, The .Heaning of Economic Imperialism por James O'Connor. Este trabajo presentado en el Centro para el Estudio de las Instituciones Democráticas, el 15 de agosto de $19^{6} 7$, es parte de un largo estudio que será próximamente publicado. Para una relación del papel desemperiado por instituciones no cconómicas en la expansión de Estados Unidos ver On Imperialism de Franz. Schurman, presentado en el Centro para el Estudio de las Instituciones Democráticas el if de agosto de 1967 , e Intervention and Revolution de Richard Barnct en la obra citada, "A Natural History of the American Empirc" de WVilliam Appieman IVilliam. Canatian Dimension, Vol. + $\mathrm{N}^{\circ}$ 3, pp. 12-17. "The United States and Latin American Revolutions" de Robert Smith. Journal of Inter-american Studies, Vol. $19, N^{\circ} 1$, encro de 1962, pp. 88-10.4.
} 
El expansionismo norteamericano engendra vulnerabilidad politica. El éxito es comprado al precio de la impopularidad. La impopularidad puede llegar a ser la base de la movilización en masa antinorteamericana, como ocurrió en la República Dominicana, en Cuba y Méjico, y puede llevar al apoyo popular de los emergentes movimientos de la guerrilla armada. En una palabra, el presente equilibrio podria generar alternativas revolucionarias; no es una 'caja cerrada'. Las vias politicas parlamentarias y legales van siendo clausuradas a los reformadores latinoamericanos (Bosch, Goulart, Arbenz, Morales, etc.) y la atracción ejercida por los partidos comunistas tradicionales se ha debilitado. Sin embargo, estas mismas circunstancias están produciendo movimientos revolucionarios internacionales, tales como aquellos propuestos en las reuniones de la Organización para la Solidaridad Latinoamericana (OLAS) realizadas en La Habana en 1967 .

Los partidos comunistas latinoamericanos entran nuevamente a una etapa dé crisis tratando de relacionarse con la détente mundial entre Estados Unidos y la Unión Soviética y al mismo tiempo haciendo frente a un desafio revolucionario recientemente organizado. Las relaciones de imposición entre la Unión Soviética y los partidos fraternos han sido reemplazadas, aparentemente, por modos "colaboracionistas" más independientes para lograr acuerdos. No obstante, las directivas de los partidos latinoamericanos, nutridas durante años por el pensamiento Soviético, acostumbradas a relaciones dependientes $y$ operando en un molde politico altamente burocratizado, encuentran dificil si no imposible reorganizarse a si mismas $^{59}$.

La fosilización politica es evidente ante la ausencia de algún nuevo análisis o estrategia que sea apropiado a los cambios sociopoliticos que han ocurrido en Latinoamérica recientemente. Pese al surgimiento del capitalismo latifundista y de las élites industriales a través de Latinoamérica los partidos comunistas escriben y hablan de la revolución "antifeudal" , como si viviesen en el siglo $\times{ }^{2} 1^{60}$. A pesar de la aparición de dictaduras militares o de gobiernos civiles controlados por los militares, el partido comunista aún propone la actividad electoral parlamentaria (via pacifica electoral), como si Latinoamérica fuese Escandinavia ${ }^{61}$.

\footnotetext{
st Una critica interesante al estéril acercamiento del partido comunista olicial a la politiea de Latinoamérica la encontramos en "Espartaco" (seudónimo), "Critica del modelo politicoeconótmico de la "izquierda oficial" ". Trimestre Económi$c o \mathrm{~N}^{\circ} 121$.

(ax En los últimos años, varios sobresalientes cientificos sociales latinoamericanos han desarrollado un sofisticado análisis y discusión de la naturaleza y consecuencias de la dominación norteamericana en Latinoamérica y los nuevos modelos del desarrollo cconómico. Una excelente colección de ensayos la encontramos en La Dominación de América Latina de José Matos Mar (editor) (Lima, Perú, Francisco Moncloa, 1g68). Incluidos en la colección están los ensayos que clicazmente desafian los antiguos dogmas: "Dependencia y Desarrollo en América Latina", por Fernando Cardoso y Enzo Falctio; "Politica Nacional de Desarrollo y Dependencia Externa", de Osvaldo Sunkel; y "La Hegemonia de los Estados Unidos y el futuro de Latinoamérica", de Celso Furtado.

${ }^{13}$ Probabiemente la mejor critica a la estrategia politica comunista es Revolution in the Revolution de Regis Debray
} 
James Pelras / Estados Unidos y el nuevo equilibrio en América Latina

Donde el partido comunista es legal, su principal esfuerzo radica en organizar frentes populares, bajo la hegemonia del partido de la clase media. A cambio de esto, los comunistas negocian por favores marginales, regatean para obtener beneficios económicos para los miembros de sus sindicatos $y$ esperan que se establezcan relaciones con la Unión Soviética ${ }^{62}$.

La politica del frente popular hacia cuba es de consideración secundaria y no es lo suficientemente importante como para interrumpir las relaciones amistosas entre los comunistas y sus "socios" de la clase media. Significativamente, la opción de un cambio estructural es relegada al futuro lejano.

Donde el partido comunista es ilegal, busca un partido legal al cual apoyar. El pensamiento táctico comunista está enderezado hacia la elección entre los partidos permitidos legalmente, y así el sistema dentro del cual efectúa sus selecciones politicas depende del grado de represión del régimen. Aun bajo las dictadura de Castelo Branco, el lider comunista brasileño Luis Prestes propuso una estrategia legal, olvidando indicar a sus seguidores cómo debería ser llevada a cabo ${ }^{63}$. Paralela y complementariamente al acercamiento legal adoptado por los comunistas brasileños, la Unión Soviética negoció una serie de convenios de comercio y ayuda con el régimen brasileño. La Unión Soviética y sus adeptos ideológicos han defendido los convenios económicos con las oligarquias latinoamericanas señalando el comercio de Cuba con España. La posición de cada pais y la naturaleza de la relación económica son sin embargo algo diferentes. Cuba es una pais subdesarrollado bajo una enorme presión de los Estados Unidos. Su relación con España es puramente comercial. En cambio, la Unión Soviética no necesita del comercio con el Brasil, Colombia o Venezuela, ya que tiene muchas otras opciones. Más importante aún es el hecho que los soviéticos hayan ofrecido crédito, asistencia, y no sólo comercio, a estos gobiernos, ayudando asi a estabilizar los regimenes.

Tal como las naciones de desarrollo tardio enfrentan el problema de industrializarse en competencia con paises altamente industrializados, hoy en América Latina los grupos revolucionarios se enfrentan al problema de establecer organizaciones revolucionarias en competencia con partidos comunistas ya establecidos $y$ antiguos partidos nacionales populares. Los grupos revolucionarios de reciente desarrollo enfrentan, además la hostilidad de Estados Unidos y de las clases gobernantes de Latinoamérica, a otras

(New York: Monthly Review, 1967). La relación es continuada en Regis Debray and the Lotin American Revolution (New York: Monthly Review, tgos $)$.

ine Para una exposición más detallada de la politica comunista tal como aparece ilustrada por el partido chileno ver Politics and Social Forces in Chilean Development (Berkeley, California: University of California Press, 1969), especial. mente el capitulo $f$ : "The Polities of the Popular Front".

un Como resultado de los problemas presentados por la estrategia legal, ha habido numerosas divisiones en el Partido Comunista Brasileño. Una critica detallada de las dificultades internas del partido brazileño la encontramos en "Carta de Carlos Áarighella al Ejecutivo del Partido Comunista Brasileño solicitando su renuncia" en Pensamiento Critico N ${ }^{\circ} 7$, agosto I 667 , pp. $20 \log ^{-218}$. 
dificultades al movilizar un distrito electoral revolucionario; sindicatos burocráticamente controlados y partidos cuyos jefes están entregados a regateos dentro del statu quo y cuyos seguidores mantienen relaciones de clientes.

A pesar de la competencia organizativa de la izquierda y la represión de la derecha, significativos núcleos de revolucionarios de izquierda han emergido en varios paises, casi exclusivamente al margen de los comunistas y de los antiguos partidos nacionalistas.

El principal esfuerzo hecho en la Conferencia de oLAS, realizada en La Habana en julio de 1967, fue el intento para afrontar las diferencias de sistema que dividen a la nueva izquierda revolucionaria y los tradicionales comunistas pro-Mloscú: la incompatibilidad para mantener a una izquierda revolucionaria unida con inclusión de revolucionarios sociales que luchan por derrocar los regimenes de la clase media y los comunistas defensores de la hegemonia de esta misma ${ }^{64}$. La Conferencia de ol $s$ fue un intento para formar una nueva organización revolucionaria internacional latinoamericana. En la Conferencia se decidió que sólo serian aceptadas las organizaciones revolucionarias dispuestas a apoyar la tesis de la lucha revolucionaria armada y a diferenciarse ellas mismas de los partidos que no siguiesen ese rumbo, por ejemplo el Partido Comunista Venezolano65. Desde el punto de vista práctico, este fue un repudio a la posición de la Unión Soviética y sus partidarios en Latinoamérica. Tal como Lenin y los primeros bolcheviques pusieron 21 condiciones para ingresar a la Tercera Internacional, Fidel Castro y los revolucionarios latinoamericanos propusieron la tesis del apoyo a la lucha revolucionaria armada como requisito para ser miembro de la Nueva Internacional. La nueva estrategia recalcó la posición conservadora dependiente de la burguesia latinoamericana y asi rechazó la táctica del "frente popular". Analizando la creciente diferenciación de clases y la polarización en las áreas rurales, el documento de olas identificó al campesinado como al principal agente histórico para la revolución. Encontrando a los partidos y organizaciones actuales inadecuados para desempeñar las tareas de la lucha revolucionaria, la Conferencia instó a crear nuevas formas organizativas capaces de combinar la actividad politica con la lucha militar. Los nuevos revolucionarios latinoamericanos conciben los puestos de mando de la lucha nacional (urbana y rural) como si estuvieran concentrados en la jefatura politico-militar unificada. Estando el foco de la lucha en el campo, los nuevos revolucionarios argumentan que las jefaturas rurales directamente comprometidas en la lucha deberian trazar la estrategia apropiada. El análisis y la estrategia propuestos en la Conferencia de la OLAS estaban en

"Ver el documento de oLAs en Granma (Suplemento semanal), 27 de agosto de 1967.

"Hatl. "olas: Resolutions of the Working Commissions of the First Conference". En especial, ver el reportaje del " whité nimero uno, "Armed Struggle is the Fundamental Line", en referencia a la burguesia "nacional" en Latinoamérica. 
James Petras / Estados Unidos y el nuevo equilibrio en América Latina

desacuerdo, en los principales puntos, con el partido comunista pro-Moscú. La lucha armada con base en el campesinado y dirigida por unidades politicomilitares (guerrillas) contra la burguesia nativa y el imperialismo fue contrapuesta a la posición comunista pro-Mloscú o a los partidos con base urbana comprometidos en colaboración electoral con la burguesia progresista ${ }^{66}$.

Para aquellos paises como Uruguay, Argentina y Chile, que tienen una numerosa clase trabajadora industrial y un campesinado relativamente pequeño, ni la olAs ni los comunistas tradicionales of recieron ninguna idea para una acción radical. Partiendo de premisas diferentes en el nivel de la politica internacional (Revolución versus Coexistencia), la nueva izquierda revolucionaria y los comunistas pro-Moscú han tomado dos caminos politicos claramente divergentes: la primera empeñada en destruir el equilibrio latinoaméricano, y la otra buscando cambios a través de la adaptación a las nuevas realidades politicas.

\section{CONGLUSION}

Reaccionando vigorosamente ante las oportunidades abiertas por la détente con la Unión Soviética, Estados Unidos se ha apoderado de la iniciativa política en Latinoamérica. La politica Norteamericana ha sido dirigida hacia la estabilidad, para asi mantener la hegemonia sobre la región. Voceros ideológicos han pregonado la idea de una armonía de intereses de las dos regiones, sugiriendo que el desarrollo de una área es compatible con el de la otra. Produciendo un corte en esta ideologia, una serie de violentos conflictos internos (Cuba, República Dominicana) han llegado rápidamente a "internacionalizarse", revelando el enorme riesgo que corre Estados Unidos al estabilizar el statu quo dentro de cada pais. Los planificadores de la acción politica norteamericana trataron de desviar el foco de los conflictos bilaterales ideando un "sistema internacional". La Alianza para el Progreso fue establecida con el explicito propósito de promover reformas. Su verdadera función era la de re-estabilizar la región. El proyecto de una estrategia multinacional es paralelo y está relacionado con la creciente importancia de la corporación multinacional en la expansión norteame-

131 La "Declaración General" de la Primera Conferencia de olus señaló:

"Con el incremento en el desarrollo económico duranfé los años qué siguieron a la independencia, ciertas condiciones. favorables para el desarrollo independiente del capitalismo y la burguesia fueron creadas en Latinoamérica, pero este desarrollo fue peralizado, desviado y deformado por las penetraciones imperialistas. Sin embargo, la debilidad orgánica de la burguesia, en cuanto a destruir el latifundio se refiere, lo que tenia que ser llevado a cabo si se queria la expansión de la producción agricola $y$ del mercado interno, y la relación de sus intereses de clase con los intereses de clases de los terratenientes forzarian a la burguesía a formar una oligarquia estrechamente unida con los dueños de la tierra, $y$ directamente ligada a la casta que controla el ejërcito profesional, en cuyas manos están concentradas las palancas decisivas del poder politico.

La enorme gravitación politica que acarrea la penetración imperialista es evidente por si misma. Las mismas contradicciones entre la burguesia latinoamericana y el imperialismo norteamericano se desarrollan baja condiciones de tal supeditación que jamás toman un carácter antagónico. La impotencia de la burguesia latinoamericana es absoluta". 
ESTUDIOS I XTERNACIONALES

ricana de ultramar. La promoción hecha por el Departamento de Estado de la Fuerza Interamericana de Paz y la intervención de Estados Unidos en la República Dominicana indican el fuerte compromiso de la Administración de Johnson para proveer un clima politico favorable a la expansión económica. La casi total ausencia de alguna oposición internacional significativa, o de ayuda, deja en claro el mutuo acuerdo de los dos bloques de poder con respecto a la hegemonia de Estados Unidos en el hemisferio. 